\title{
INTER-ORGANISATIONAL SYSTEMS, STRATEGY AND STRUCTURE: THE CASE FOR PLANNING ENVIRONMENTS
}

\author{
Pat Finnegan*, Robert Galliers** and Philip Poweli\# \\ *Executive Systems Research Centre, \\ University College, Cork, \\ Ireland \\ E-mail: P.Finnegan@ucc.ie \\ **Information Systems Research Unit, \\ Warwick Business School, \\ University of Warwick, \\ Coventry, CV4 7AL, UK \\ \# Dept. of Maths and Computing Sciences, \\ Goldsmiths College, \\ University of London, \\ New Cross, London, UK \\ E-mail: orspp@razor.wbs.warwick.ac.uk
}

\begin{abstract}
Electronic trade and commerce have brought inter-organisational co-operation to the forefront of organisational strategies. However, inter-organisational systems (IOS) planning lacks appropriate methodological guidelines, and tends to be practised in an insular manner. This paper examines the development of systems in three interorganisational networks in lreland in order to ascertain the planning that went into them. The nerworks studied are representative of three types of structural interdependencies - pooled, reciprocal and sequential. Although it is difficult to identify an activity that can be clearly labelled IOS planning, planning is integral to the development of all networks. The interdependencies influence planning processes and outcomes. For the pooled and reciprocal networks, the planning process gives a focus. For the sequential network, the main planning is done by the hub organisation, and extended to the spokes. Planning interactions across all networks illustrate similarities that reveal that existence of planning environments within which IOS planning takes place. These planning environments are proposed as being an appropriate basis for the development of IOS planning guidelines.
\end{abstract}

\section{INTRODUCTION}

A number of researchers have argued that, in order to cope with its environment and reduce environmental uncertainty, an organisation should link with others (e.g. Van de Ven, 1976; Provan, 1982; Borman, 1994). Such links encourage inter-organisational communication and co-ordination, and thus reduce environmental uncertainty (Eisenberg $e t$ al., 1985). While consideration of the potential of inter-organisational co-operation has been advocated since the 1960s (Kaufman, 1966), it is the recent possibility of electronic trade and commerce (Kuula, 1995) that has brought inter-organisational co-operation to the forefront of organisational strategies. Yet, inter-organisational systems (IOS) planning lacks guidelines, and tends to be practised in an insular manner (Finnegan et al., 1998).

This paper examines the development of systems in three inter-organisational networks, in order to examine the basis of the planning underpinning them. The networks represent three types of structural interdependencies which influence planning processes and outcomes. However, planning interactions across the networks illustrate similarities that reveal that existence of archetype planning environments within which inter-organisational systems planning takes place. These environments may form the basis for the development of IOS planning guidelines.

The paper begins by considering the role of inter-organisational systems in the development of electronic trade and electronic commerce. This highlights the need for planning. Next the research framework is set out. The research findings are then analysed in terms of strategy, planning, infrastructure, organisational activity and personnel. This leads to the identification and discussion of planning environments.

\section{ELECTRONIC TRADE, COMMERCE AND INTER-ORGANISATIONAL SYSTEMS}

The terms electronic trade, electronic trading and electronic commerce are essentially synonymous, and refer to trading transactions that are conducted using electronic media (Kuula, 1995). Byles (1993) defines electronic commerce as 'the use of electronic information and network systems for the transmission and recording of the many kinds of communications in a commercial transaction'. Cunningham and Tynan (1993) refer to electronic trading as 'any trading relationship which relies upon the use of computer technology for inter-organisational communications, normally involving telecommunication links'. These definitions agree on the use of telecommunications to conduct commercial transactions, but differ according to the type of market to which they 
refer. Electronic trading is business-to-business transactions in an industrial context, while electronic commerce refers to retailing and the consumer sector as well as mass marketing (Kuula, 1995).

Electronic trading systems exploit information technology to improve the efficiency of communications and/or to alter the nature of inter-organisational transactions. Electronic trading systems and extra-organisational systems are inter-organisational systems designed to operationalise electronic business opportunities as shown in figure 1 .

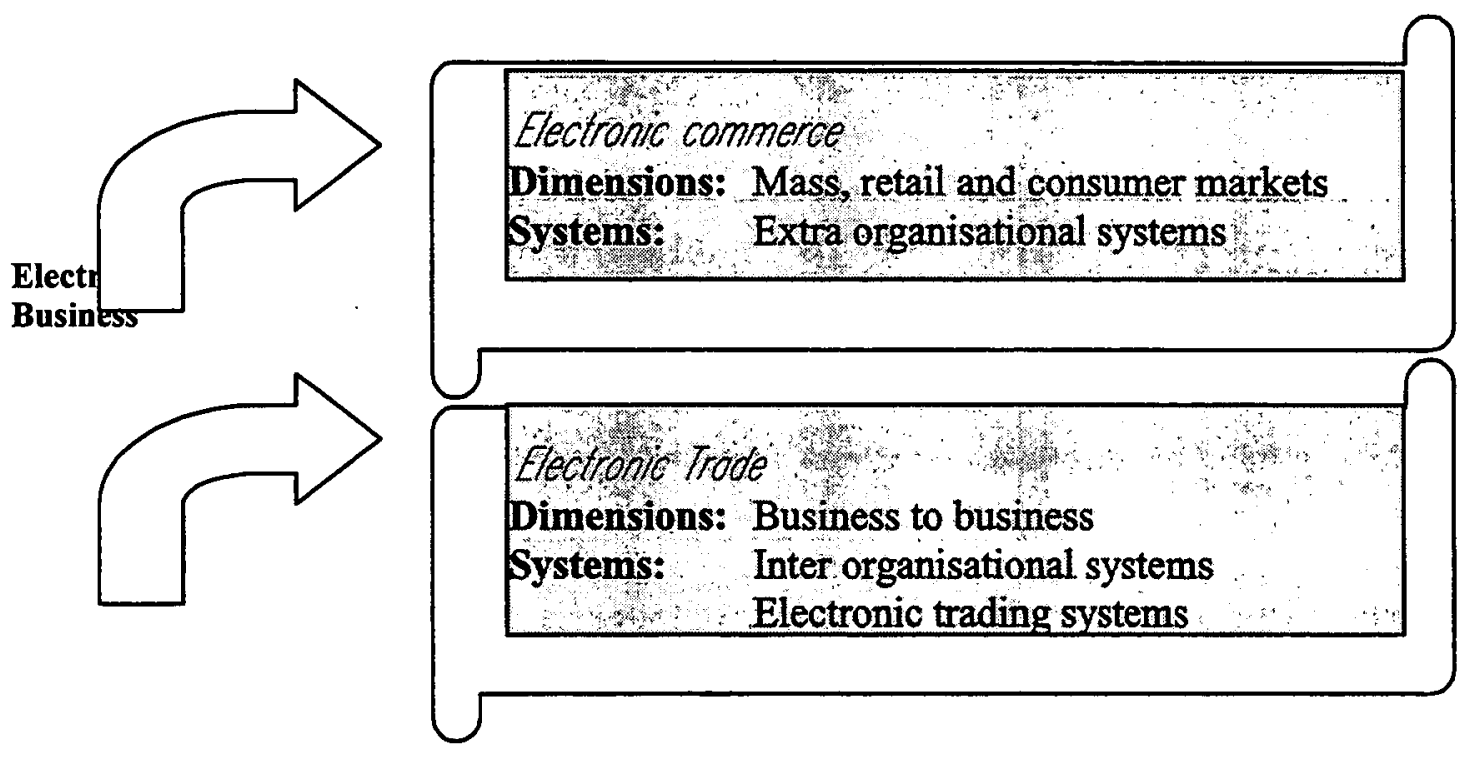

Figure 1: $\quad$ Electronic business and IOS

An element common to both electronic trading and electronic commerce is the use of electronic marketing channels. This refers to the electronic applications that provide the mechanism for purchasing and selling products and services. Such channels are also referred to as electronic linkages or electronic connections, which are, in general, associated with inter-organisational systems (Kuula, 1995).

Inter-organisational systems can positively affect inter-organisational transactions by reducing costs and improving efficiency (Swatman and Swatman, 1992; Cox and Ghoneim, 1994). In addition, they reduce environmental uncertainty by facilitating communication and providing information (Henderson, 1990; Bergeron and Raymond, 1992; Scala and McGrath, 1993). Finally, they can also affect the competitive positioning of organisations by encouraging closer relations with suppliers and customers (Cash and Konisynski, 1985; Swatman and Swatman, 1992; West, 1994). This diversity of inter-organisational functions is reflected in the variety of $1 O S$ available.

Based on the work of Thompson (1967) and Robey and Sales (1994), Kumar and Van Dissel (1996) propose a topology of inter-organisational systems. In this topology, IOS are categorised according to the level of organisational interdependency they facilitate. Interdependency means conditions where organisations rely on, or are influenced by, others in relation to their operations or financial welfare. Kumar and Van Dissel's categorisation includes pooled interdependency, sequential interdependency, and reciprocal interdependency as shown in table 1.2.

Pooled IOS involve the sharing of IS/IT resources, value/supply-chain IOS facilitate customer-supplier relationships along the value chain, and networked IOS operationalise reciprocal inter-dependencies such as joint ventures and strategic alliances. These interdependencies range along a continuum from pooled to reciprocal, with those further along the scale inheriting the characteristics of the earlier ones. Further, as organisations may be involved in more than one type of inter-organisational relationship, a particular IOS may exhibit characteristics of more than one type of interdependency (Kumar and Van Dissel, 1996).

The importance of this topology is that Kumar and Van Dissel (1996) recognise that inter-organisational structures, and the design, implementation and operation of IOS are inter-dependent. This means that organisational structures affect systems choices rather than the traditional view that technology affects structures only. Inter-organisational systems development is consequently constrained by more factors than just technology. This is also demonstrated by research on IOS success. Organisational factors are consistently found to be more important than technical factors in determining IOS success (Clarke and Jenkins, 1993; Holland $e t$ al., 1994; Finnegan and Golden, 1996). Of these, planning is regarded as the most important in influencing the success of inter-organisational systems (Finnegan et al., 1998b). 


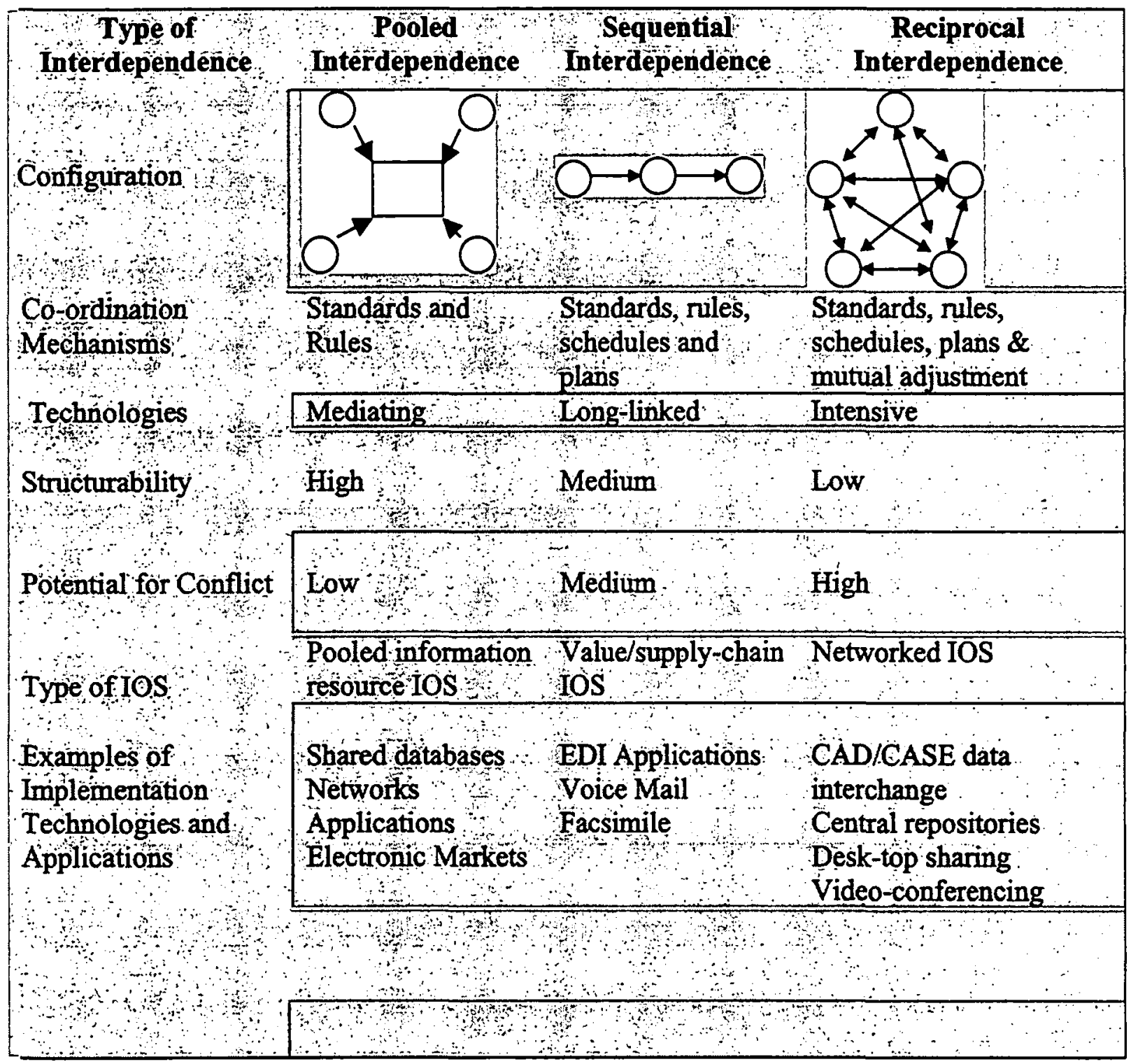

Table 1: An IOS topology (from Kumar and Van Dissel, 1996)

The need for planning

The advent of inter-organisational systems and the growth of electronic commerce presents new challenges for IS planning processes. The few existing IOS planning guidelines are fragmented and focus on individual IOS technologies such as electronic data interchange (EDI) and group technology (Holland and Lockett, 1990; Opper, 1994). These technological guidelines assume that IOS planning is accommodated within existing IS planning processes as just another technology, and neglect the fundamental non-technical aspects of IOS planning and its organisational base. While emerging technologies such as EDI and the Internet may be accommodated within existing planning structures, the need to involve external parties, and the associated issues of co-operation and control are outside the frame of reference of existing planning efforts. In addition, the interorganisational structure (Kumar and Van Dissel, 1996) which provides the context for planning is significantly different especially in terms of its complexity.

While some IS planning methods consider analysing the external environment as an integral part of the planning process, they do not deal with issues of designing and developing information systems that transcend organisational boundaries. Although some systems have been successfully developed within a single organisation and utilised across organisational boundaries (e.g. American Hospital Supplies), these systems have 
tended to arise in a somewhat serendipitous manner and, by and large, control has remained with the developing organisation. In addition, recent research has indicated that the real benefits of inter-organisational systems go hand in hand with high levels of business and technological change. This means that organisations need to make substantial changes to their activities, structures and systems in order to take full advantage of IOS. It is unlikely that such high level changes will not occur by a one organisation imposing systems onto others, though there are examples of this e.g. Webster (1995).

Given the above and the limited exploratory empirical research on IOS planning, research that examines the planning and deployment of inter-organisational systems in order to explain the nature of IOS planning appears to be timely.

\section{THE RESEARCH FRAMEWORK}

It was decided to adopt a case study research method given the exploratory nature of the research and the need to obtain rich data in the complex inter-organisational contexts under examination. 'A case study examines a phenomenon in its natural setting, employing multiple methods of data collection to gather information from one or a few entities (people, groups, or organisations). The boundaries of the phenomenon are not clearly evident at the outset of the research and no experimental control or manipulation is used' (Benbasat et al., 1987). Yin (1984) proposes that case studies are most appropriate when the research objective involves studying contemporary events, without the need to control variables or subject behaviour. The strength of case studies is their ability to capture reality in greater detail, and to analyse more variables than is possible with any other method (Galliers, 1991). Pettigrew (1992) proposes that context and action are interwoven in the study of strategy and it is important to consider the past and present when looking to the future. This further justifies the choice of case methods, as it emphasises contextual understanding and emphatic research objectives (Gable, 1994).

Within the case method, a multiple case study research design was devised so as to facilitate the collection of context data on IOS planning within a natural setting. Eisenhardt (1989) suggests that fewer cases are more suitable when there are mini cases within the larger ones, as here. Three inter-organisational networks were selected on the basis of type and structure of network, type of planning experience and technology and systems used. The study includes examination of the planning processes of partner / participant firms in the interorganisational network. The case studies were chosen to give diversity in the nature of inter-organisational networks rather than any preconceived notion of best practice.

A combination of data collection methods was used. The primary methods were personal interviews and document analysis. The choice of personnel was based on willingness to co-operate, involvement in IOS implementation, nature of knowledge, and seniority. Each interviewee was asked to indicate the most appropriate personnel to speak to regarding the development of the network. A small number of people were involved in each case due mainly to the personal nature of the planning activity. The third network contained a larger number of participants, but even here there were a small number of key decision makers. All those identified as key personnel were interviewed where possible. Those interviewed had both technical and general business backgrounds, and included senior and middle management.

The networks are classified as examples of pooled dependency, sequential dependency, and reciprocal dependency as described by Kumar and Van Dissel (1996). As shown in table 2, these systems can also be categorised as being examples of inter-organisational systems (IOS) and extra-organisational systems (EOS) in their support of electronic trade and commerce. For confidentiality reasons, the organisations are referred to by pseudonyms.

Network 1 operates in the pharmaceutical industry and is an example of pooled interdependency. The network uses an open standard inter-organisational system, co-operatively developed by wholesalers and pharmacies during the mid-1980's in order to share information on product pricing and availability, and to act as an electronic market for ordering.

Network 2, an example of sequential dependency, uses EDI based inter-organisational systems operating between a retail supermarket and its suppliers operating in the grocery retail sector in Ireland. The main systems used relate to invoicing, price catalogues, credit notes, and dispatch advice.

Network 3 is a group of 15 independent organisations from different European states, operating as a virtual organisation providing and promoting technologies for business process transformation. This network delivers on-line products and services over the Internet to European organisations engaged in business process redesign. 


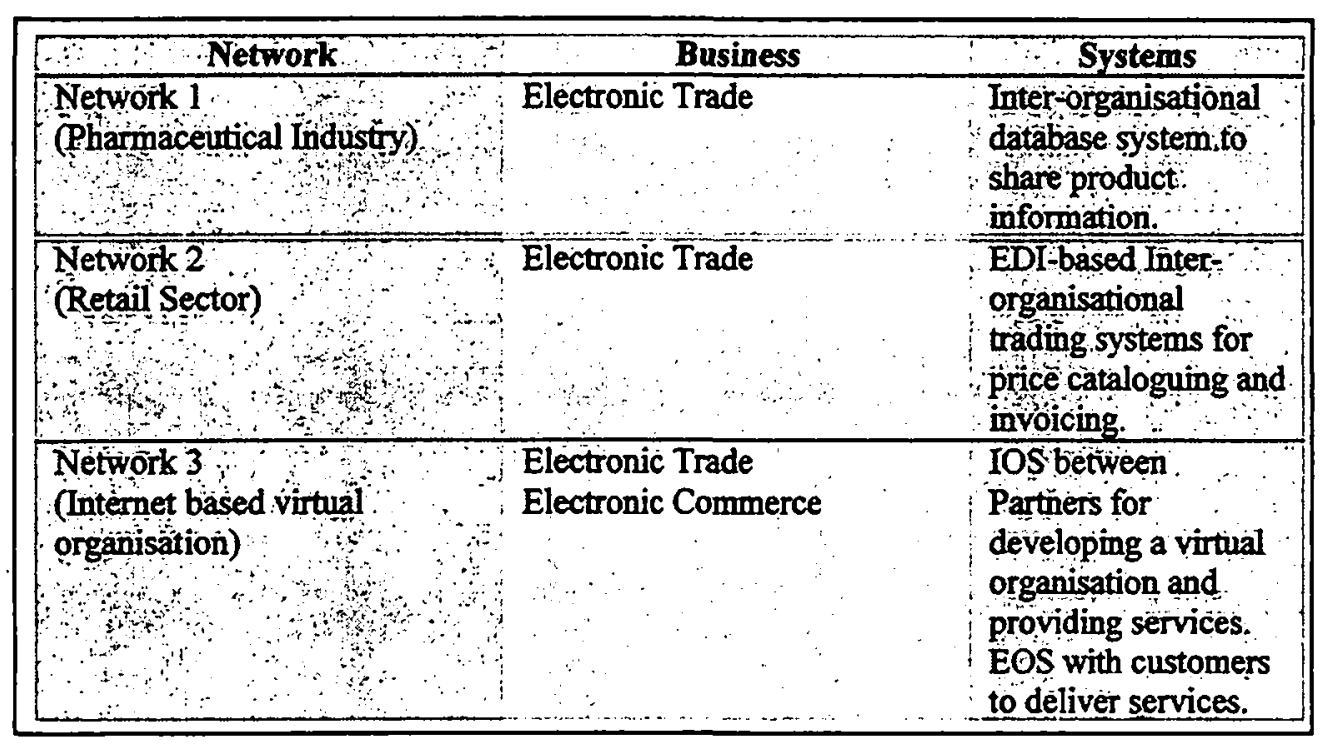

Table 2: Inter-organisational networks studied

\begin{abstract}
ANALYSIS
Examination of IOS planning in the networks reveals that, while little thought was given to planning processes in any of the organisations studied, planning was nevertheless perceived to be an important aspect of the developments. Such planning tends to have similar features in all three networks, despite a lack of formal debate on the form that the planning should take. In many ways the planning in these networks displays many characteristics of the organisational IS planning approach described by Earl (1993), where planning is a continuous decision making activity shared by the business and IS. The results show that planning has a more important role than just identifying and prioritising systems projects in that it contributes to the development of inter-organisational systems by helping to establish co-operation as well as negotiating systems and other details within the confines of inter-organisational influence and objectives. In addition, planning is, in many ways, a negotiation tool used by IOS participants to establish inter-organisational arrangements, in addition to delineating systems products. Analysis of the findings shows that the interaction of the individual organisational planning approaches with the reality of an inter-organisational operating environment produces a series of planning environments. IOS planning is seen to take place with these environments, which influence IOS planning processes and outcomes. Inter-organisational activity in relation to systems and organisational activity illustrate these planning environments, as discussed in the following sections. These planning environments are proposed as being the basis for developing IOS planning guidelines.
\end{abstract}

\title{
Introducing Inter-Organisational Systems: Strategic Issues
}

While the methods used illustrate an informal approach to planning, all systems were introduced as participant organisations deemed them an important aspect of their business strategy. The inter-organisational systems are diverse in their relationships with the business strategies. Individual organisations and networks use business strategy in different ways, but all use it as a tool for implementing inter-organisational systems. The necessity of making a business case for IOS within individual organisations is recognised, but IOS champions tend to use business strategy in an opportunistic manner rather than as a guiding set of objectives. The evidence suggests that IOS planners must ensure that the business strategy is conducive to IOS rather than having to drive IOS. The business strategy angle is useful in two ways: first as a selling tool, both internally as well as between organisations; and second, as a tool for reaching a co-operative decision by negotiation.

All organisations take account of the expectations of their business strategy, yet it was clear that a formal association between IOS planning and business planning did not usually exist. A wholesaler in the pharmaceutical industry was the only firm studied that stated that its interest in IOS was the result of a top-down business-driven strategy. According to the IT manager 'the push for this system came from the top'. The CEO visited the US in the early 1980s and examined electronic ordering systems being implemented by American wholesalers. On return he asked the IT department to investigate the technical possibilities and employed a person to market the concept to pharmacists. The company was in the process of developing their own systems when the pharmacist representatives approached them with a view to developing a co-operative system. This can be contrasted with the two other networks where the linkage was less formal. One IS manager in the retail 
sector, who had been involved in developing a business strategy two years previously, stated 'I have not seen the [business strategy] document since, and am not really sure what the current strategy is...electronic trade has become part of the business strategy, rather than business strategy driving electronic trade'.

Despite the lack of a formal network strategy, those responsible for IOS in individual organisations know what their organisation expected from them, and how IOS could help realise these expectations. For some partners within the third network, the Internet-based systems were simply an extension of services that they currently provided manually. Although in some cases they were unsure of the role that IOS would eventually play in their business, it was clear that it was important to be involved. According to one partner 'we have to be involved as this project directly affects our business. It would be unwise to let ourselves become a competitor rather than a partner'.

A knowledge of business expectations is useful in recognising opportunities for applying technical solutions, but IT people realise that agreement between senior business managers in the organisations concerned is necessary to introduce IOS; this is perceived as beyond the remit of IS personnel. The IS manager in one of the retail sector organisations believes that 'the real decisions are made between the IS people in trading organisations; senior executives are brought in to formalise the process'. A business case has to be made, but this is done after the IS manager has decided what should be done, and how it should be done.

Therefore, the relationship between business strategy and IOS can best be described as fragmented. IOS is based more on the strategies of individual organisations rather than on a network strategy. It is these individual strategies that led organisations to work together within the network, and, in many cases, the network strategy emerged from the collective strategies of network participants rather than being formulated in advance. However, it is notable that, where one organisation had a more powerful position in the market than others, their strategy became the default network strategy. Nevertheless, network strategies are more likely to be visions rather than formulated objectives from which more detailed, lower level plans can be developed. Lower level decision making and planning appears, therefore, based very much on negotiation among participants based on their own goals. This is where the realities of business strategy are incorporated.

\section{Planning Fundamentals}

Planning within the three networks studied takes place within a business framework that tries to take advantage of the emerging technology. It has both strategic and operational aspects. The strategic element provides direction within a business rationale, and the operational aspects concentrate on implementation of the technical infrastructure. Yet, IOS planning is more emergent than formal. This is especially true in relation to the role that the systems would play in the networks, and the contribution such systems would make to participants' businesses. Technical details at an operational level received more detailed planning attention.

A conscious decision was not made on a network-wide basis to engage in IOS planning. The realities of interconnecting systems demanded precise technical details and operational procedures, while the emerging nature of the available technology and the uncertainty surrounding its co-operative potential resulted in short planning horizons and conservative expectations among many IOS participants. The retail sector manager in the leading value added network (VAN) for EDI was sure that planning took place. She believed that it was generally the hub (central) company that did the planning, 'The hub sets its objectives, decides on how to move forward and then draws up a list of suppliers'. This scenario is typical of EDI in the retail sector. It is necessary to have a strong proponent, both within an organisation and in the network. However, it does not have to be the hub company. One of the spoke organisations in the retail sector, because of its size, dependence on EDI and commitment to developing EDI-based systems, was very involved in planning. However, when the IS manager in this organisation was questioned on planning, her response was 'what planning?' She did not see that planning took place. However, when questioned further, it became evident that she knew exactly what direction the inter-organisational systems would take. Her policy was to decide on what to do and then convince customers to request the systems, 'A request from an important customer is strategic enough to get the board's approval'. This personal approach to IOS planning was also evident in the other network studied. In each, someone provided direction for the development of systems within the network.

Even with a strong proponent leading IOS strategy, IOS planning requires lower level decision making. An examination of this reveals that IOS planning decisions are taken in one of two ways. One is that the issues are debated among participants to reach a solution. Alternatively, one member made the decision and sold it to the others. Many of these decisions concerned details relating to technology issues or process requirements. Power and influence of key players within the network are an important element of how these decisions were made, regardless of whether the decision making process was by negotiation or by decree. The hub company and the VAN in the retail sector made the technical decisions. Decision making in the other two networks was more cooperative in nature. However, partners with technical expertise were very influential in this process. Nevertheless, the nominal involvement of all interest parties in the decision appears to have made implementation of the technical decisions easier. 


\section{Systems Infrastructure}

Planning begins as a learning process where organisations attempt to find out about IOS technologies and what they can provide in specific circumstances. This helps create a business argument that is used to conceptualise the nature of the systems to be implemented. This process is inter-woven with issues of the nature of data to be exchanged. Finally, an implementation process is planned. A dominant partner who imposes or sells these decisions to trading partners can undertake all these processes. Alternatively, the processes can be more cooperative. Nevertheless, knowledge of the technology or experience of its use elsewhere proves an advantage in convincing trading partners to support the ideas.

\section{Learning}

A key part of the IOS planning processes in the networks studied is leaming about the technology. This learning is double faceted in that it considers technical functionality and systems capabilities. In addition to providing information on available technology, this leaming can be important in achieving co-operative momentum or as a selling aspect to bring other organisations on board. 'Achieving co-operation is the hardest part of the process' according to a pharmacy owner, 'however, once you get co-operation on one issue, you create a precedence which helps the next time'. This co-operation is important in getting agreement when influence is equally distributed among participants. It also helps to build trust, which is an essential element in benefiting from IOS.

Knowledge of the success of a particular technology in similar applications elsewhere is an important starting point in creating a vision for using that technology. This vision can then be used as a selling point, both within and without the organisation, for bringing others on board. The CEO from one drug wholesaler went to the US to study electronic ordering systems. Pharmacists were reading about IOS elsewhere and were anxious that a situation such as the American Hospital Supplies, where wholesalers installed the systems, would not happen to them. The owner of a chain of pharmacies acknowledged that an agreement is more likely to be accepted if someone can support their argument with evidence from elsewhere'. Representatives from the retail sector on the ANAI (Article Numbering Association of Ireland) sub committee on EDI studied the influence of EDI technology elsewhere, while the spread of Internet-based electronic commerce initiatives was central to creating the vision in the third network. Consequently, the business justification of adopting such technology is based on creating a systems-based argument that illustrates how it can help meet business objectives.

\section{Technology and Systems Planning}

The inter-organisational systems infrastructure is planned around IOS technology. The choice of technology is a natural output from the learning process discussed above. In one case, an open system was developed because pharmacists did not want to be tied into one standard. They considered TRADACOMMS but rejected it, according to one IT manager, as 'it was a sledge hammer to crack a nut'. Inter-organisational systems in the retail sector are EDI-based because of the commitment of IT personnel in this sector to introducing the technology. Internet-based systems are used in the third network because it is central to the electronic commerce aspirations of its founders.

Participants perceive that detailed nature of IOS technology planning is a necessity because of the decision making required in relation to standards and protocols used to operate systems between organisations. These decisions are an important part of the planning process because they can limit the size and nature of the interorganisational network. However, the systems infrastructure is specifically planned around what the technology can provide to meet the business requirements. These business objectives then get translated into systems concepts.

Planning the systems infrastructure has both internal and external considerations. Technical planning at the network level focuses on major approaches and technologies. For example, the decision to adopt EDI was made by representatives of the grocery industry. Such decision making can either be the result of a co-operative process or the acceptance by trading partners of the decision of one partner. Following these decisions, an internal planning process within individual companies must deliver their individual responses. The contrast between internal and network objectives can be seen from the efforts by a drugs wholesaler to develop a standard that would meet their internal requirements and still be acceptable as a network solution. According to the IT manager, 'such planning would be much easier if you could control both ends. Things are more difficult when it is necessary to co-ordinate independent parties'.

Overall, technology and systems planning on an inter-organisational basis appears to be a case of marrying the objectives and the capabilities of participants. This is perhaps more co-operative than some other activities, but knowledge and influence are still leveraged as part of the decision process. Technical constraints are a limiting factor which need to be examined as part of the planning process in order to facilitate inter-organisational interaction. Often these technical constraints focus on the transmission of data between organisations.

Systems planning must necessarily consider data to be transmitted. Arguments for the development of IOS often 
come from using the data to meet a business need. For example, organisations that choose to implement an invoicing system will have already considered the broad outline of the data it will contain. Structured data systems such as those in the retail sector require detailed consideration of data sources, fields, presentation forms etc. The issue of availability of data is central to IOS planning by the hub company in the retail sector. According to the EDI manager, 'the ability to send data in the correct form at the right time is crucial to the success of the system. Much of the planning for new installations is, therefore, concerned with getting this data in an appropriate form'. However, this form is not decided in conjunction with the supplier. EDI standards adopted by the hub dictate what must occur.

The planning of systems implementation is a natural follow-up to planning and designing the systems and data infrastructures. Issues considered during this process relate to timing, sequence, technical capabilities etc. Implementation planning in a situation where one organisation controls the process is less complicated than where it is necessary to get co-operative agreement. In a co-operative situation, participants are more likely to try to get the implementation plan to suit their own goals.

\section{IOS and Organisational Activity}

The concerm by technical people for IOS technology and the involvement of senior managers in the strategic elements of IOS cover two main elements in introducing IOS. Inter-organisational systems also affect the way in which individual organisations, as well as organisational networks, conduct their activities and cover issues of process, procedural and structural changes. Those introducing IOS, despite claims that they constitute an important element of IOS benefits, rarely consider such changes. The degree to which such changes are considered appear to be related more to the objectives of individual organisations rather than to a network strategy. However, it is clear in the short term, that certain network cultures are more likely to produce activity changes than others.

In terms of affecting organisational processes, IOS starts as a technical issue that tends to spread into other facets of the organisation. A pattern starts to emerge whereby the IT people champion the systems and technology, and convince senior management and functional areas to adopt it. When the systems become stabilised, they become the responsibility of the functional area. Process changes occur at this level rather than as a result of top-down planning. However, some procedures may be developed as part of the process. The situation that led to the development of the pharmaceutical systems was different. Inter-organisational systems were seen as central to process improvement. Wholesalers wanted electronic ordering to reduce the overhead associated with teleordering, while pharmacists were 'keen to reduce the time spent on administrative duties such as ordering'. However, such process issues were internal considerations, and did not form a large part of the interorganisational planning process. Nevertheless, these issues were key to the system's development.

Procedures for using inter-organisational systems can be manual or computerised. They are, therefore, a necessary element of IOS planning. These procedures can be categorised as those that operate across the network and those that apply to a particular organisation because of their adoption of the IOS. Procedures that relate to network activities require the involvement of other parties, or at least a consideration of their needs. A dominant partner such as a hub organisation or systems expert can heavily influence such procedures. In the third network, procedures were prototyped by the technical partner and commented upon by others. According to one partner, 'generally, procedures relating to the technology were accepted, but adjustments were made to data related procedures where other partners had ideas on how certain things should be done. These were generally from within that partner's area of expertise or directly affected their activities'.

It is clear that the effects of inter-organisational systems on structure are not a consideration for those implementing IOS. The potential of such systems to affect organisational structure is realised, but it is most certainly not planned for. The benefits of IOS can be felt in many departments, but structural alterations are not in the forefront of the minds of those planning them. However, according to one partner in the third network, 'as a virtual organisation, a completely new organisational structure was being created using 1OS'. However, while at a high level this structure was planned, roles and their consequential structural issues emerged as opposed to being formulated, 'The structures being created were dependent on the organisations involved. These structures were centred around areas of expertise, and evolved more than were planned'. In fact, when the planning process started to consider explicit roles and tasks within the context of delivering a commercial product, it based much of its decision making on the roles that participants already fulfilled.

\section{IOS and Personnel}

This section investigates planning aspects of the effects of IOS on staff. Staff can feel such effects in two ways. First, there is the issue of skills required to implement the systems, and second, there are changes in roles, responsibilities and activities of personnel whose function is affected. The study finds that both these aspects of electronic business are considered secondary to the technology issue, and were approached in a bottom-up manner. IT skills received more attention than organisational skills as they directly affect the daily operations of 
the IT department. This is often seen as a once-off training issue, whereas the organisational skills issue is more on-going and developing.

The effects on IT staff were considered in the IT department in the hub company in the retail sector. According to the EDI manager 'the selling of the EDI concept by vendors necessitated a consideration of how EDI would affect the IT department'. Systems development was undertaken internally with the advice of the EDI VAN. Existing personnel who also deal with internal systems undertook this development. The technology is not seen as radically different and extemal interests are considered where necessary, rather than involving them in the planning process.

Considerations of changing organisational roles are limited in the context of IOS planning. This is especially true when the IOS is instigated by a dominant partner, and where minimal changes are made. More co-operative inter-organisational situations are more likely to change organisational structures as the negotiation process involved in their establishment is more complex and is likely to examine structural change.

Changes in organisational roles have occurred for sales people within one furm in the retail sector. Fewer sales people are required than before. Therefore, some consideration of the effects on the sales department had to be undertaken. This was done by the IS manager in conjunction with the sales director. The nature of the sales activity changes when customers commit to implementing EDI in that it not only becomes more stable, but also places different challenges on the sales people. This requires some retraining, but more important is the role of the surplus sales people. Key here is that issues of changes in organisational roles are worked out between the heads of the functional areas concerned. This was not seen as central to the IOS planning process, however.

\section{DISCUSSION AND CONCLUSIONS}

The above analysis shows that $\operatorname{IOS}$ exist in many different contexts, even within the same network. Such diversity is evident in the IOS planning approaches adopted by the participants. Although it can be difficult to identify an activity that can be clearly labelled IOS planning, planning was integral to the development of all networks. For the pooled and reciprocal networks, the planning process gave a focus to the activities and helped the projects gain momentum. For the sequential network, the main planning was done by the hub organisation, and was extended to the spokes in order to bring them on board. This stand-alone approach to planning was possible because of the power of the hub organisation. This power helped negate the need to gain co-operation by engaging in joint planning. Instead of having to use planning as a process for gaining consensus, it could focus on transactional details that needed to be applied in order to implement the inter-organisational system. However, even within these networks, it is clear that influence and co-operation played an important role in planning activities.

Business and IS planning processes are important for setting objectives and formulating plans to meet the targets. These activities are based on organisational requirements for coordinated activity. Within the IOS domain there is also a need for setting objectives and targets. However, IOS planning has a far more important role than just giving direction. This role is in achieving co-operation, and is related to the setting in which the interorganisational system is being developed. This co-operative role is most evident in the networks characterised as pooled and reciprocal interdependency. However, certain inter-organisational activities across all networks are based on co-operation, while others are based on the power and influence of an individual or organisation. The result is a complex inter-play of planning environments that not only influence the planning process, but also the resulting system.

In an attempt to understand IOS planning environments, it may be useful to describe them as lying along a continuum, characterised as ranging from monarchist to club. The characteristics of the extremes are shown in table 3.

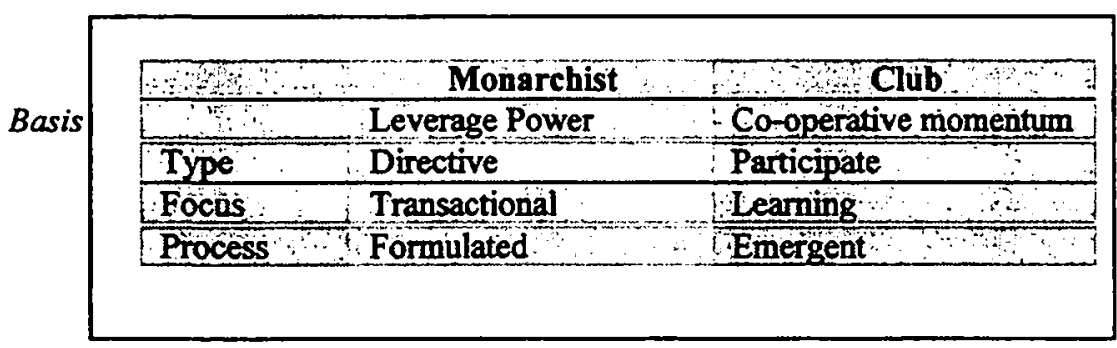

Table 3: Monarchist and Club IOS planning environments

The monarchist environment is based on a strong organisation that holds some power over others in the network. For example, a large retailer has power over a series of small suppliers. Planning in this case is traditional in that 
the dominant organisation can set the objectives and design a process where others in the network must meet objectives. Planning is directive and focuses on transactional issues such as technical standards, budgets, and timescales. A traditionally formulated IOS planning process is often appropriate in this case, as the issues are more clear-cut.

At the other end of the scale, the club environment is based on the premise that no single organisation dominates. The planning process is more participative as those involved need to accommodate each other's needs and expectations. This is more a learning environment where strategies evolve. Transactional issues become relevant here in two ways. First, as part of the learning process where a co-operative network strategy emerges, and second, as the implementation issues after co-operation has been achieved. The planning process here is often emergent rather than formulated, although a more formulated process may be used for the transactional elements. It is clear that many different planning environments operated within the networks studied. However, a broad classification would suggest that network two (retail sector) was mostly monarchist and network three (virtual organisation) was mostly club, with network one (pharmaceutical) operating in between these two. However, even within these classifications others are evident. For example, technical issues with network three were mostly approached in a monarchist manner.

The type of planning required, therefore, falls into two categories. One is a co-operative learning activity, the other a discrete, formulated process that focuses on tasks, budgets and technical standards. Low level issues such as standards and budgets are required in all networks, while the higher level learning activity is required where there is a need for a co-operative approach to IOS implementation. In arguing that IOS planning processes should be based on inter-organisational relations rather than an extension of internal systems planning, the basis for developing IOS planning guidelines starts to emerge. However, it is clear that these guidelines must be based around the realities of inter-organisational relations and systems requirements. The importance of these guidelines is emphasised by the 'soft' nature of the existing organisational approach to planning, which is recognised by Earl (1993) as a weakness of such approaches.

Planning frameworks are required at both the level of the individual organisation and at the network level. This is necessary in order to provide participants with a mechanism to consider both internal organisational issues and issues that affect the whole network. The development of these frameworks needs to result from an analysis of the role played by each participant. Once planning frameworks have been established, it is necessary to determine which roles each participant organisation need to play, and who within the organisation is most suited for the roles. This is not necessarily an issue of psychology, but rather the IOS planning process must provide an opportunity for such issues to be considered. IOS need to be the result of an objective that contributes to business strategy or an organisational structure/activity need. Consequently, planning efforts must consider these issues in a thorough and complete manner. This is especially important as inter-organisational systems become more widespread and affect more of the value chain. Finally, IOS planners must deal with systems, data and technology issues. While IOS planners may borrow from internal approaches in this regard, it is necessary to realise that even these issues are complicated by their existence within an inter-organisational domain.

\section{REFERENCES}

Benbasat, I, Goldstein, D. K. Mead, M. (1987) "The case study research strategy in studies of information systems", MIS Quarterly, 11 (3) 369-386.

Bergeron, F. and Raymond, L. (1992) "The advantages of electronic data interchange", Data Base 23 (4) 19-30.

Borman, M. (1994) "Common knowledge, interorganisational networks and the future for the organisation of production", Journal of Information Technology, 9 203-212.

Byles, T (1993) "Electronic Commerce: The new foundation for trade", EDI FORUM: The Journal of Electronic Data Interchange, 6 (3) 12-17.

Cash, J.I. and Konsynski, B.R. (1985) "IS redraws competitive boundaries", Harvard Business Review, (2) 134-142.

Clarke R. and Jenkins M. (1993). "The strategic intent of on-line trading systems: A case study in national livestock marketing", Journal of Strategic Information Systems 2 (1) 57-76.

Cox, B. and Ghoneim, S. (1994) "Benefits and barriers to adopting EDI in the UK: A sector survey of British industries", in Baets, W.R.J. (ed.) Proceedings of the Second European Conference on Information Systems, Nijenrode University, The Netherlands, May 30-31.

Cunningham, C. and Tynan, C. (1993) "Electronic trading, inter-organisational systems and the nature of buyerseller relationships: The need for a network perspective", International Journal of Information Management, 13 3-28.

Earl, M.J. (1993) "Experiences in strategic information systems planning", MIS Quarterly, 17 (1) 1-24.

Eisenberg, E.M., Farace, R.V., Monge, P.R., Bettinghaus, E.P., Kurchner-Hawkins, R., Miller, K.I. and Rothman, L. (1985) "Communication linkages in interorganisational systems: Review and synthesis" in Dervin, B. and Voigt, M.J. (eds) Progress in Communication Sciences vol. 6, Ablex Publishing Corporation, Norwood, N.J. 
Finnegan, P. and Golden, W. (1996) "Key success factors for late adopters of inter-organisational systems: A non-technical perspectives from Irish organisations", Proceeding of the 29th Hawaii International Conference on System Sciences, 377-386.

Finnegan, P. Galliers, R. D. and Powell, P. (1998) Inter-organisational systems planning: Leaming from current practices, International Journal of Technology Management, forthcoming.

Finnegan, P., Golden, W. and Murphy, D. (1998b) "Implementing Electronic Data Interchange: A non-technical perspective", International Journal of Electronic Commerce, 2 (4).

Gable, G. (1994) "The case study in IS research", Proceedings of the Searcc Conference on IT, Kuala Lumpar, Malysia, August 11-14.

Galliers, R.D. (1991) "Choosing appropriate information systems research approaches: A revised taxonomy", in Nissen, H.E., Klein, H.K. and Hirschheim, R. (eds.) in Information Systems Research: Contemporary Approaches and Emergent Traditions, Proceeding of the IFIP TC8/WG 8.2 working conference, Copenhagen, Denmark.

Henderson, J.C. (1990) "Plugging into strategic partnerships: The critical IS connection", Sloan Management Review, Spring, 7-18.

Holland C.P., Lockett G., Richard J.M. and Blackman I. (1994). "The Evolution of a Global Cash Management System", Sloan Management Review (Fall), 37-47.

Holland, C.P. and Lockett, A.G. (1990) "An implementation model for electronic data interchange", Proceedings of the International Conference on Information Management, Budapest, 675-685.

Kaufman, F. (1966) "Data systems that cross company boundaries", Harvard Business Review, Jan-Feb, 141.

Kumar, K. and Van Dissel, H.G. (1996) "Sustainable collaboration: Managing conflict and co-operation in interorganisational systems", MIS Quarterly, 20 (3) 279-300.

Kuula, J. (1995) Inter-organisational Information Systems as a Media for Supporting the Internationalisation of Business, Ph.D. Thesis, University of Jyvaskyla, Finland.

Opper, S. (1994) "Choosing and implementing a groupware system", Datapro.

Pettigrew, A.M. (1992) The character and significance of strategy process research. Strategic Management Journal 13 5-16.

Provan, K.G. (1982) "Interorganisational linkages and influence over decision making", Academy of Management Journal, 25 (2) 443-451.

Roby, D. and Sales, C.A. (1994) Designing Organisations, Irwin, Homewood IL.

Scala, S. and McGrath, R. (1993) "Advantages and disadvantages of electronic data interchange: An industry perspective", Information and Management, 25 85-91.

Swatman, P.M.C. and Swatman, P.A. (1992) "EDI system integration: A definition and literature survey", The Information Society, 8, 169-205.

Thompson, J. (1967) Organisations in Action, McGraw-Hill, New York, NY.

Van de Ven, A.H. (1976) "On the nature, formation and maintenance of relations among organisations", Academy of Management Review, October, 24-36.

Webster, J., (1995) Networks of collaboration or conflict? Electronic data interchange and power in the supply chain. Journal of Strategic Information Systems, 4 (1) 31-42.

West, L.J. (1994) "Breaking down the barriers to EDI implementation", TMA Journal, 14 (1) 10-15.

Yin, R.K. (1989) Case Study Research: Design and Method, Sage Publications, CA. 